A reduction in heavy polysomes after starvation has been observed in liver ${ }^{4,5}$. Our results show that starvation for $24 \mathrm{~h}$ causes disaggregation of polysomes and increase in free alkaline ribonuclease activity. Such alterations in polysomes following starvation have been attributed to increase in ribonuclease activity ${ }^{5}$.

Résumé. Le profil des polysomes et l'activité de la ribonuclease alcaline libre se modifient dans le placenta et le foie maternel des souris à la suite d'inanition et de l'exposition aux rayons $\mathrm{X}$.

U. Tarachand and J. EApen

Biology and Agriculture Division,

Bhabha Atomic Reseavch Centve,

Bombay 400085 (India),

27 June 1973.

\title{
Formation of Lipoperoxide in Brain Edema Induced by Cold Injury
}

The mechanism of the occurrence of brain edema is one of the most urgent problems to be elucidated in the field of neurosurgery. As a mechanism of the occurrence of brain edema, DEмopoulos et al. ${ }^{1}$ suggested that free radical reactions may be involved in the damage to the membrane structure in the brain. However, no such experimental data have been reported. Since the provocation of brain edema by cold injury, according to the method of KLATzo et al. ${ }^{2}$, has been well established, we tried to adopt this experimental edema for demonstration of the participation of free radicals in this disorder.

Male Wistar rats, $150-200 \mathrm{~g}$, were used as experimental animals. Cold injury was made as described by KLAtzo et al. ${ }^{2}$. After the rats were anesthesized with urethane ( $1 \mathrm{~g} / \mathrm{kg}$ body weight, injected i.p.), the parietotemporal cranial bone was exposed and fenestrated in a round form (1.5 $\mathrm{mm}$ in diameter). A column of dry ice was attached lightly to the dura mater for $20 \mathrm{sec}$. At definite time after the cold injury, the brain was removed and the right hemisphere was taken for the analysis of lipoperoxide. Lipoperoxide was determined by thiobarbituric acid method ${ }^{3}$ modified by Nishigaki et al. ${ }^{4}$ as follows. The hemisphere was homogenized in $5 \mathrm{ml}$ of cold $0.9 \% \mathrm{NaCl}$ solution and $4 \mathrm{ml}$ of the homogenate was mixed with $1 \mathrm{ml}$ of thiobarbituric acid reagent $(0.67 \%$ thiobarbituric acid aqueous solution + glacial acetic acid, $1: 1, \mathrm{v} / \mathrm{v})$. The mixture was heated at $100^{\circ} \mathrm{C}$ for $1 \mathrm{~h}$. After cooling, it was shaken with $5 \mathrm{ml}$ of chloroform, and centrifuged at $3000 \mathrm{~g}$ for $10 \mathrm{~min}$. The supernatant was centrifuged further at $10,000 \mathrm{~g}$ for $10 \mathrm{~min}$, and clear supernatant obtained was subjected to absorbance measurement at $532 \mathrm{~nm}$. The animals which were treated in the same manner except for the cold injury were adopted as controls.

The results are summarized in the Table. As can be seen from the table, the lipoperoxide formation reached its maximum $12 \mathrm{~h}$ after the cold injury, but the development of the brain edema and the destruction of the bloodbrain barrier were most prominent $24 \mathrm{~h}$ after the injury ${ }^{5}$. It is clear from these observations that the brain edema

Increase in the amount of lipoperoxide in the cold-injured brain

\begin{tabular}{lll}
\hline Time after injury & Controls & Cold-injured brain \\
\hline $30 \mathrm{~min}$ & $5.38 \pm 0.31(3)$ & $6.01 \pm 0.56(4)$ \\
$12 \mathrm{~h}$ & $5.45 \pm 0.56(4)^{\mathrm{a}}$ & $7.14 \pm 1.13(4)^{\mathrm{a}}$ \\
$24 \mathrm{~h}$ & $5.13 \pm 0.25(4)^{\mathrm{b}}$ & $6.01 \pm 0.50(4)^{\mathrm{b}}$ \\
$48 \mathrm{~h}$ & $5.32 \pm 0.38(5)$ & $5.63 \pm 0.63(5)$ \\
$\mathrm{DM}(24 \mathrm{~h})$ & $5.01 \pm 0.19(6)$ & $5.26 \pm 0.56(6)$
\end{tabular}

The data represent nmole malonaldehyde formed per $g$ wet weight of the brain, obtained by thiobarbituric acid method. Numbers of experiments are shown in parentheses. Statistically significant increase was observed in both $a(p=0.05)$ and $b<0.05\}$. DM: treated with dexamethasone (see text). was established at a definite period after the injury. This means that the mechanism of the occurrence of the edema involves some successive processes of changes in the brain. The lipoperoxide formation, demonstrated in the present study, would occur in association with the above processes. Probably the damage that is brought about by the cold injury liberates the agent(s), such as hemoglobin, to provoke free radicals that promote the peroxidation, which brings about further enormous damage in the membrane. Consequently, water and other extracellular substances can permeate easily into the brain perenchyma.

Since the effect of steroids on the cold-injured edema was reported by PAppius and $\mathrm{MCCANN}^{6}$, the effect of dexamethasone on the lipoperoxide formation in the present edema was studied. The animal was injected intraperitoneally with $0.5 \mathrm{mg} / \mathrm{kg}$ of dexamethasone $1 \mathrm{~h}$ before the cold injury and further with $0.5 \mathrm{mg} / \mathrm{kg}$ of it $6 \mathrm{~h}$ after the cold injury to examine the effect of this drug on the lipoperoxide formation. The animal was killed $24 \mathrm{~h}$ after the injury, and the lipoperoxide in the brain was measured as mentioned above. As listed in the table a remarkable preventive effect of dexamethasone on the lipoperoxide formation was found. This might be ascribed to its stabilizing effect on membrane, mainly during the stage of the cold injury.

The present data support the supposition of the usefulness of steroids in prevention of human brain edema. Also, the use of antioxidants is considered to be effective to prevent and treat the brain edema as described by ORTEGa et al. ${ }^{7}$, but such antioxidants have to be non-toxic and preferably permeable to the blood-brain barrier.

Zusammenfasşung. Biochemische Untersuchung zur Frage der Membranschädigung bei experimentellem Hirnödem: Lipoperoxid tritt $12 \mathrm{~h}$ nach der Traumatisierung in der höchsten Konzentration auf, was pathogenetisch bedeutungsvoll sein könnte.

Osamu Suzuki and Kunio Yagi

Institute of Biochemistry, Faculty of Medicine, University of Nagoya, Nagoya (Japan), 4 July 1973.

1 H. B. Demofoulos, P. Milvy, S. Kakari and J. Ransohoff, in: Steroids and Brain Edema (Eds. H. J. REULEN and K. SchürmANn; Springer-Verlag, Heidelberg 1972), p. 29.

$\Rightarrow$ I. Klatzo, A. Piraux and E. J. Laskowski, J. Neuropath. exp. Neurol. 17, 548 (1958).

3 F. Bernheir, M. L. C. Bernheim and K. M. Wilbur, J. biol. Chem. 174, 257 (1948).

4 I. Nishiga KI, T. OzAWA and K. YAGI, Vitamins, Jap. 38, 359 (1968).

5 O. SuzUKI, MI. NaOr, M. Takanohashi and K. Yagr, unpublished results.

6 H. M. Pappius and W. P. McCann, Arch. Neurol. 20, 207 (1969).

7 B. D. ORtega, H. B. Demopoulos and J. Ransofoff, in: Steroids and Brain Edena (Eds. H. J. ReveEN and K. SCHURHANN; Springer-Verlag, Heidelberg 1972), p. 167. 